\title{
Study of Placental Pathology in Cases of Intrauterine Fetal Deaths
}

\author{
Pramod Dharmraj Borade, Sujata R. Kanetkar, Pradnya Pandurang Kale*, Atul Bhanudas Hulwan \\ Dhirajkumar B. Shukla and Nikita Vinod Vohra
}

Department of Pathology, Krishna Institute of Medical Sciences, Karad, Maharashtra, India

\section{ABSTRACT}

Background: Intrauterine fetal death is agonizing, often unpredictable event. The mother, the fetus, and the placenta all are involved in the complex process of fetal death and therefore, should be addressed together. Unfortunately, the cause of death is unexplained sometimes up to two third of intrauterine deaths. For the proper determination of the cause, and further prevention, Placenta is the most accessible and readily evaluable specimen which is mirror image of pregnancy.

Methods: This cross-sectional study was carried out in the Department of Pathology in a tertiary care hospital from June 2015 to May 2017. Material for the present study comprised of 99 placentas obtained from the cases of IUFD, delivered in the Department of Obstetrics and Gynecology of a tertiary care hospital. These 99 placentas were received in the Department of Pathology along with clinical details for histomorphological study.

Result: Histopathological examination of placenta revealed following findings - Perivillous fibrin 62/99 (62.62\%) cases, calcification 51/99 (51.51\%) cases, intervillous hemorrhage 46/99 (46.46\%) cases, prominent syncytial knots 45/99 (45.45\%) cases, cytotrophoblastic proliferation $41 / 99$ (41.41\%) cases, increased vascularity 31/99 (31.31\%) cases, fibrinoid necrosis 19/99 (19.19\%) cases, hydropic villi 09/99 $(09.09 \%)$ cases and villitis in $07 / 99(07.07 \%)$ cases.

Conclusion: The placenta can be considered as the diary of pregnancy. After fetal death, it remains viable for several days. The value of examining the placenta determining cause of death in intrauterine fetal death is evident and varies from $28-85 \%$. The value depends largely on the quality of the placental reports.

\section{Keywords: Intrauterine Deaths, Placental Changes in Diabetes, Placental Changes in Hypertension.} Perivilloius Fibrin, Intervillous Haemorrhage.

\section{Introduction}

Intrauterine fetal death is agonizing, often unpredictable event. The mother, the fetus, and the placenta all are involved in the complex process of fetal death and therefore, should be addressed together. Examination of placenta provides record of pregnancy, in which the cumulative effects of pregnancy related events and changes reflecting the intrauterine environment can be scrutinized.

Unfortunately, the cause of death is reported as unexplained sometimes up to two third of intrauterine deaths. ${ }^{[1,2]}$ There is intensifying demand on medical, social, and epidemiological grounds for proper determination of the causes.

Considering the above facts, the study of Placental Pathology plays an important role in the diagnosis of causes of fetal death and prevention of further recurrences.

Worldwide, about 4 million intrauterine fetal deaths reported officially each year. In developing countries, 1 in 200 pregnancies results in intrauterine fetal death. ${ }^{[3]}$ Rate of perinatal deaths in India is 32 per 1000 live births, 35 per 1000 live births in rural areas and 22 per 1000 live births in urban areas. Stillbirth rate in India is 9 per 1000 live births. ${ }^{[4]}$ The placenta can be considered as the diary of pregnancy. After fetal death, it remains viable for several days. The value of examining the placenta for determining cause of death in intrauterine fetal death is evident and varies from $28-85 \%{ }^{[5,6]}$ The value depends largely on the quality of the placental reports.

The present study was undertaken to study the placental pathology in cases of intrauterine fetal death.

\section{Materials and Methods}

Study of Placental Pathology in cases of Intrauterine Fetal Death was a cross sectional study carried out in the Department of Pathology in a tertiary care hospital from June 2015 to May 2017 for detection of placental pathology of intrauterine fetal death.

Material for the present study comprised of 99 placentas obtained from the cases of IUFD, delivered in the 
Department of Obstetrics and Gynecology of a tertiary care hospital. These 99 placentas were received in the Department of Pathology along with clinical details for histomorphological study.

Inclusion criteria: All placentas received in the histopathology section from cases of intrauterine fetal death of gestational age more than 28 weeks were included in the present study.

Exclusion criteria: Autolysed placentas.

The placentas were collected soon after delivery. The gross examination of membranes, cord and placental disc was done. Fresh weight and size of placental disc were noted. The largest and the smallest diameters were recorded in centimetres and thickness was measured at the centre of the placental disc.

Placental Disc: Placental disc was examined and cut according to technique described by Fox H. (1964-1978). ${ }^{[7]}$

Fetal surface: The fetal surface was inspected for color and translucency of membranes. Vessels were inspected for any thrombosis or calcification. Subchorionic fibrin if present in excess was noted. Examined the membranes on the fetal surface first, and checked for nodules within or just below the amnion/chorionic layer.

Maternal surface: Maternal surface was examined for its intactness, retroplacental hematoma, calcification, infarction and depressions. Any unusual shapes or extra lobes were noted.

Then entire placenta was cut in a bread-loafing manner at 0.5 to $1 \mathrm{~cm}$ intervals. The slices were examined for any gross lesions. Infarcts, intervillous thrombus and cysts etc. were noted. The placentas were kept for fixation for a period of minimum one week.

Sampling- After complete sectioning and inspection of the cut surface of the placenta, careful selections of representative blocks of placental tissue were done.

1) Placental Disc- Two blocks were taken from the grossly intact placental tissue from the basal plate of the central region of the placenta. Two full thickness sections of the placenta, including both chorionic and basal plate were taken from the peripheral area from two different placental lobules.

Additional sections were also taken from abnormal area, if any.

2) Membranes- Benirschke ${ }^{[8]}$ technique of taking a membrane roll for histopathological examination was adopted. After inspection of the membranes, a segment of approximately $10 \times 5 \mathrm{~cm}$ was cut out. This segment of membranes was then firmly rolled by means of forcep and placed in fixative, where it hardens. After fixation it was trimmed so that a jelly-roll like structure was obtained for histological examination. This rolling has the advantages of allowing study of a large area of membranes.

3) Umbilical Cord- Umbilical cord was cut-off from the disc at a point about $2-4 \mathrm{~cm}$ above its insertion into the fetal surface.

After fixation all the tissue bits were processed by routine paraffin tissue processing method and 3-5 $\mathrm{mm}$ thick sections were cut on microtome. All sections were stained by routine hematoxylin and eosin (H\&E) stain. All slides were examined microscopically. Grossly abnormal areas were examined microscopically and findings of gross were confirmed.

\section{Result}

The present cross-sectional study was carried out in Department of Pathology of a tertiary care hospital from June 2015 to May 2017. Study of Placental Pathology in Intrauterine Fetal Death cases comprised of 99 placentas. The IUFD rate in the present study was 20.91/1000 live births. Among 99 cases of IUFD, 67 (67.67\%) cases were emergency admissions and remaining 32 (32.33\%) admissions were registered ANC cases.

Maximum cases of IUFD 49/99 (49.49\%) cases were found in 21 to 25 years of maternal age group. IUFD was found to be more common in primigravida 50/99 $(50.50 \%)$ mothers. Maximum IUFD 72/99 (72.72\%) cases were from gestational age group of 28-36 weeks, i.e. preterm IUFD were more common than term and post term cases.

Maximum number of IUFD were male 66/99 (66.67\%) with male to female ratio 2:1. Maximum number of placentas 79/99 (79.80\%) were weighing between 200-500 $\mathrm{gm}$. Among all the fetuses with intrauterine death, 50/99 cases $(50.51 \%)$ were having birth weight ranging from 2 to 2.99 kilogram and BMI of their mothers was ranging from 18.5-24.9.

Causes of IUFD were divided into four categoriesMaternal, placental, fetal and other. Maternal disorders $(70.70 \%)$ formed the major category followed by placental (24.25\%), fetal (4.04\%) and other (1.01\%). The commonest maternal condition leading to IUFD was PIH $43 / 70(61.42 \%)$ cases followed by anemia 18/70 (25.71\%) cases. Gestational diabetes mellitus was observed in $3 / 70$ (4.28\%) cases, $\mathrm{Rh}$ incompatibility 2/70 (2.85\%) cases and a single case from Bad obstetric history and Jaundice respectively. (Table No. 1) 
Among the placental causes of IUFD 16/24 (66.66\%) cases had Abruptio placenta followed by Oligohydramnios 4/24 (16.66\%) cases and PROM and placenta previa $2 / 24(8.33 \%)$ cases each. In order of frequency gross pathological findings observed in placentas were as follow: - Calcification 51/99 (51.51\%) cases (Figure No. $01)$, Infarcts $36 / 99(36.36 \%)$ cases and retroplacental hematoma 28/99 (28.28\%) cases. (Table No. 2).

Histopathological examination of placenta revealed following findings: - Perivillous fibrin 62/99 (62.62\%) cases (figure No. 2), calcification 51/99 (51.51\%) cases (figure No.1), intervillous hemorrhage 46/99 (46.46\%) cases, prominent syncytial knots $45 / 99(45.45 \%)$ cases, cytotrophoblastic proliferation $41 / 99(41.41 \%)$ cases, increased vascularity 31/99 (31.31\%) cases (Figure No. 03), fibrinoid necrosis 19/99 (19.19\%) cases, hydropic villi 09/99 (09.09\%) cases and villitis in 07/99 (07.07\%) cases (Figure No. 04).

Majority of placenta $73 / 99(73.74 \%)$ cases showed eccentric insertion of umbilical cord followed by $21 / 99$ $(21.21 \%)$ central insertion. Chorioamnionitis and amnion nodosum, as lesions of membrane were observed in 24 cases of IUFD. (Table No. 3 and 4).

Table 1: Showing various maternal causes contributing to IUFD.

\begin{tabular}{|c|c|c|}
\hline Maternal causes of IUFD & Number of cases $(\mathbf{n = 7 0 )}$ & Percentage (\%) \\
\hline PIH & 43 & 25.76 \\
\hline Anemia & 18 & 4.28 \\
\hline GDM & 03 & 2.85 \\
\hline Rh incompatibility & 02 & 2.85 \\
\hline Hypothyroidism & 02 & 1.42 \\
\hline BOH & 01 & 1.42 \\
\hline Viral Hepatitis & 01 & 100 \\
\hline Total & 70 & \\
\hline
\end{tabular}

Table 2: Showing various placental causes of IUFD.

\begin{tabular}{|c|c|c|}
\hline Placental causes of IFUD & Number of cases $(\mathbf{n = 2 4 )}$ Percentage (\%) \\
\hline Abruptio placenta & 16 & 66.66 \\
\hline Oligohydramnios & 04 & 16.68 \\
\hline PROM & 02 & 8.33 \\
\hline Placenta Previa & 02 & 8.33 \\
\hline Total & $\mathbf{2 4}$ & $\mathbf{1 0 0}$ \\
\hline
\end{tabular}

Table 3: Showing distribution of gross findings in placenta from cases of IUFD.

\begin{tabular}{|c|c|c|c|}
\hline Cause of IUFD & $\begin{array}{c}\text { Calcification } \\
(\mathbf{n = 5 1 / 9 9 )}\end{array}$ & $\begin{array}{c}\text { Infarct } \\
(\mathbf{n = 3 6 / 9 9 )}\end{array}$ & $\begin{array}{c}\text { Retroplacental } \\
\text { hematoma(n=28/99) }\end{array}$ \\
\hline PIH & 28 & 19 & 07 \\
\hline Anemia & 08 & 01 & 00 \\
\hline GDM & 02 & 00 & 01 \\
\hline Rh incompatibility & 00 & 00 & 00 \\
\hline Viral hepatitis & 01 & 05 & 14 \\
\hline Abruptio placenta & 04 & 00 & 00 \\
\hline Oligohydramnios & 02 & 01 & 00 \\
\hline PROM & 01 & 01 & 00 \\
\hline Placenta Previa & 02 & 01 & 00 \\
\hline Post dated pregnancy & 01 & 00 & 00 \\
\hline Twin pregnancy & 01 & 00 & 00 \\
\hline Congenital anomaly & 01 & 01 & 00 \\
\hline H/O fall & 00 & 00 & 00 \\
\hline
\end{tabular}


Table 4: Showing microscopic findings in placenta from all cases of IUFD.

\begin{tabular}{|c|c|c|}
\hline Microscopic Findings & Number of cases $(\mathbf{n = 9 9 )}$ & Percentage (\%) \\
\hline Perivillous fibrin & 62 & 42.62 \\
\hline Intervillous haemorrhage & 46 & 45.46 \\
\hline Syncytial knots & 45 & 41.1 \\
\hline Cytotrophoblastisc proliferation & 41 & 31.31 \\
\hline Increased vascularity & 31 & 16.16 \\
\hline Fibrinoid necrosis & 19 & 09.09 \\
\hline Hydropic villi & 09 & 07.07 \\
\hline Villitis & 07 & \\
\hline
\end{tabular}

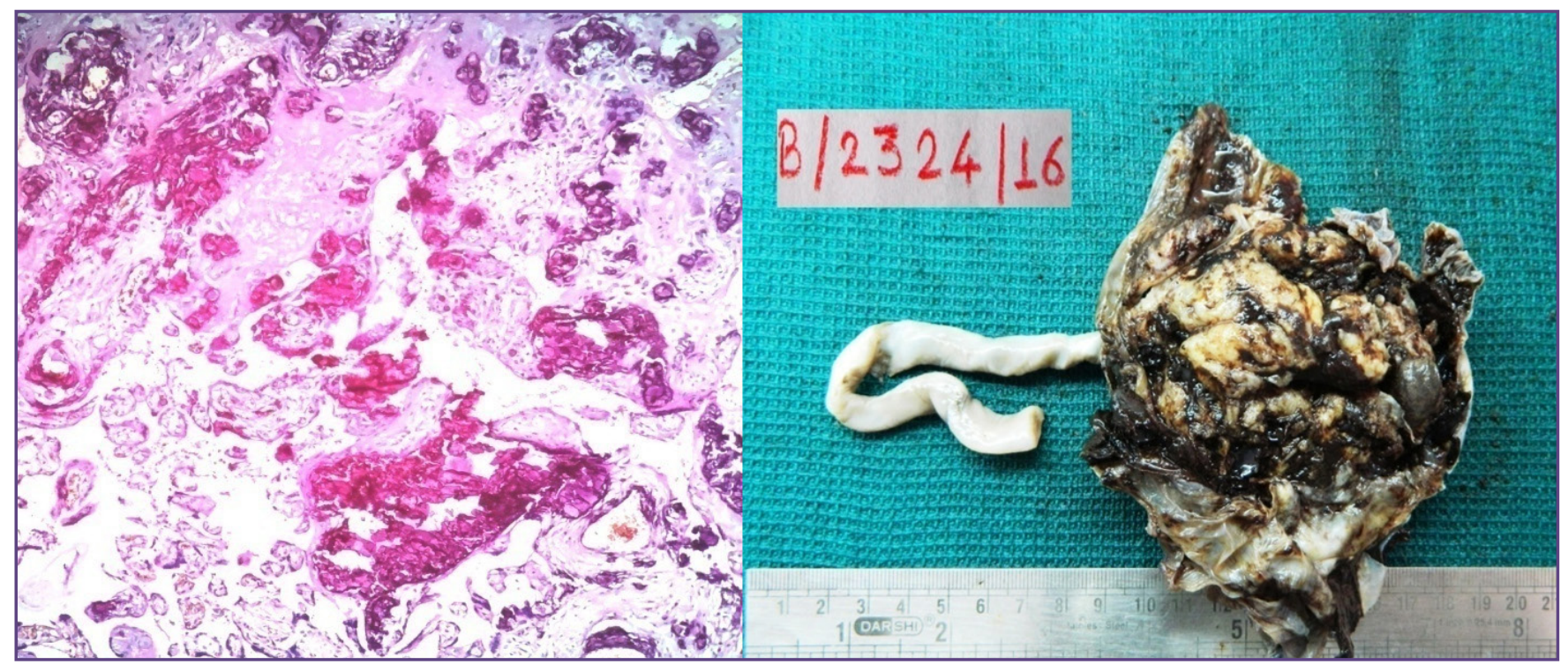

Fig. 1: Photograph and photomicrograph (100X, H \&E) of extensive placental calcification.

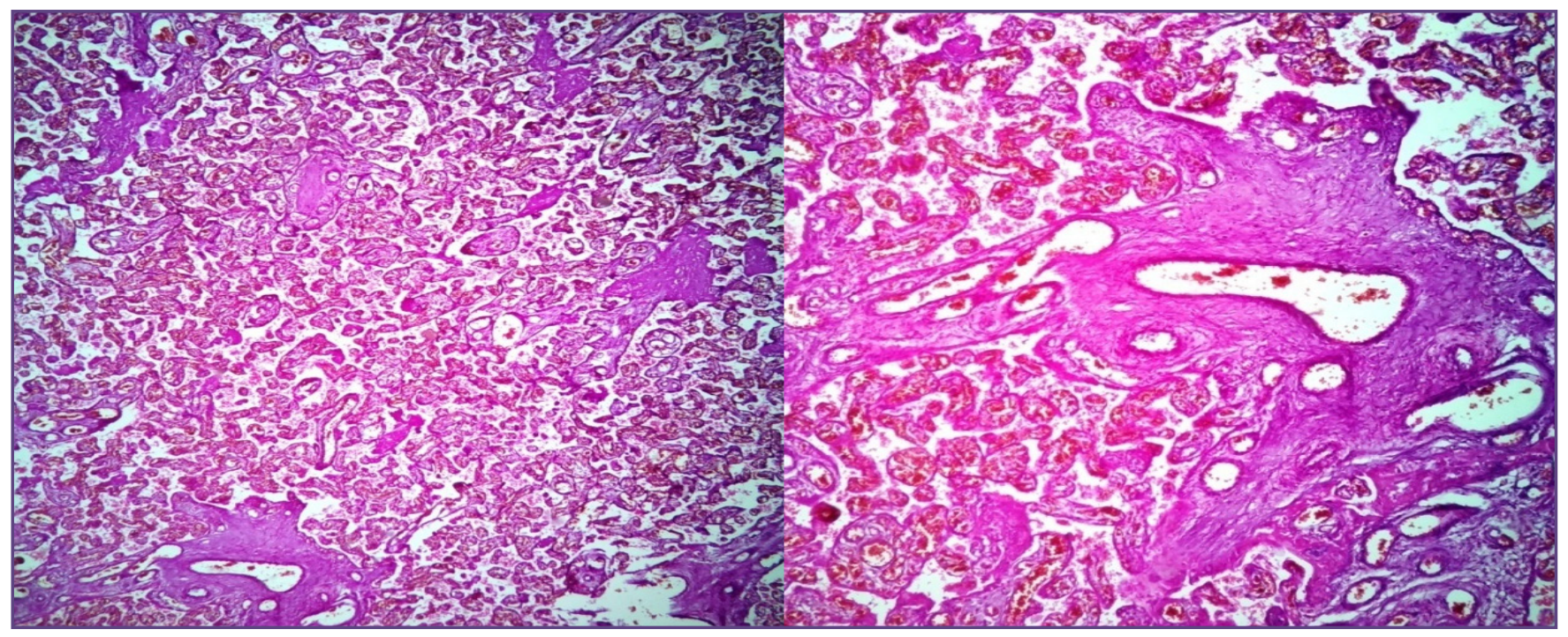

Fig. 2: Photomicrographs of perivillous fibrin (H \& E, 100X and $400 \mathrm{X}$ ). 


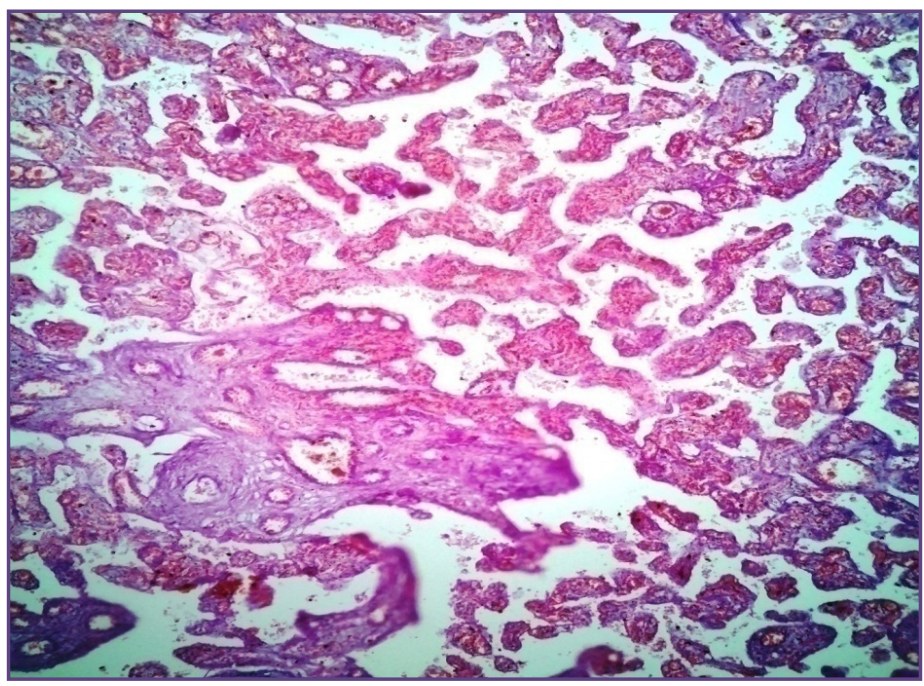

Fig. 3: Photomicrograph showing increased vascularity (H\&E, 40X)

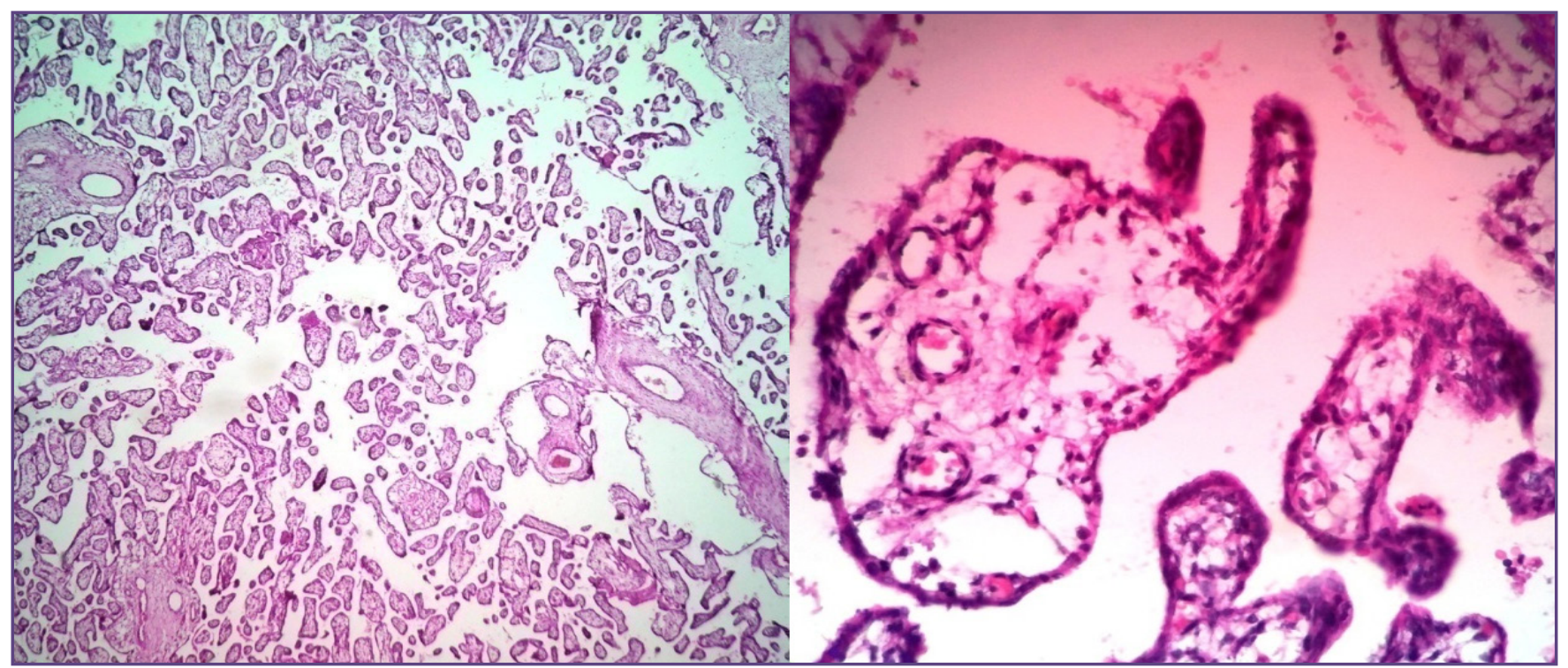

Fig. 4: Photomicrographs of edematous villi with villitis (H \& E, 40 X \& 400 X).

\section{Discussion}

In order to study Placental Pathology in Intrauterine Fetal Deaths, both maternal clinical parameters as well as placental pathology need to be taken into an account. In the present study, it was observed that IUFD was more commonly seen in maternal age 21 to 25 years, which was most common reproductive period. This finding was in accordance with the study done by Patel S et al (2014) ${ }^{[9]}$, and Dave A et al (2016). ${ }^{[10]}$

Majority of cases 74/99 (74.74\%) were in the normal BMI category and belonged to age groups 21 to 30 years i.e. the period of maximum reproducibility. Ellen Aagaard Nohr et al (2005) ${ }^{[11]}$ and Singh $\mathrm{N}$ et al (2013) ${ }^{[12]}$ were also noted similar findings in their study.
Gravida of the mother influences pregnancy outcome. Among the intrauterine dead fetuses $50.50 \%$ were born to primigravida, followed by $46.47 \%$ in multigravida. Present study was in concordance with study done by Ujwala $\mathrm{CH}$ et al (2013) $)^{[13]}$ and Sharma I et al (2016) ${ }^{[42]}$ showing majority of cases of IUFD in primigravida.

Gestational age of most of the fetuses with intrauterine death ranged from 28 to 36 weeks $(72.72 \%)$ i.e. preterm IUFD. Similar finding was noted in study done by Prasanna $\mathrm{N}$ et al (2015), Dave A et al (2016). ${ }^{[10]}$

Maximum number of IUFD cases 50/99 (50.51\%) was noted with fetal weight in between 2 to $2.99 \mathrm{kgs}$. This finding was similar with study done by Singh N et al (2013) ${ }^{[12]}$ and Prasanna N et al. (2015). ${ }^{[15]}$ 
In the present study IUFD was more in males $66.67 \%$ as compare to females. Tamrakar SR et al (2012), ${ }^{[16]}$ Ujwala $\mathrm{CH}$ et al (2013) $)^{[13]}$ and Dave A et al (2016) ${ }^{[10]}$ also reported male preponderance in their study.

In present study $79 / 99(79.80 \%)$ cases belonged to placental weight in between 200 to 500 gms, 18/99 (18.18\%) cases showed placental weight less than 200 gms and only two cases had a placental weight more than 500 gms.

Causes of IUFD: Frequency of IUFD from Maternal disorders $70 / 99(70.70 \%)$ cases contributed the major clinical presentation followed by placental causes 24/99 (24.25\%) and fetal causes 04/99 (04.04\%) and a single case from history of fall from stair case i.e. trauma. Similar findings were observed in the study done by Shagufta $\mathrm{S}$ et al (2006), ${ }^{[17]}$ Ujwala $\mathrm{CH}$ et al (2013) $)^{[13]}$ and Prasanna $\mathrm{N}$ et al (2015) ${ }^{[15]}$ showed maternal causes were a leading cause of IUFD followed by placental and fetal causes of IUFD respectively.

Placental pathology in Cases of Pregnancy Induced Hypertension (PIH): In the present study we found that 43/99 cases (43.43\%) of PIH causing IUFD( Table No. 1 ). Choudhari A et al (2014), ${ }^{[18]}$ Prasanna N et al (2015), [15] Patel S. et al (2016) ${ }^{[19]}$ were also reported PIH as leading cause of IUFD. Present study was in corroboration with this study. In present study it was found that PIH 29/43 case (i.e. 67.44) was more common in pre-term IUFD. This is in comparable to the study by Balu D et al (2015) ${ }^{[20]}$.

Placentas were smaller in $\mathrm{PIH}$, calcification were seen in $28 / 43(65.11 \%)$ cases being commonest finding, large multifocal infarcts 19/43 (44.18\%) cases and 10/43 $(23.25 \%)$ cases showed large retroplacental hematoma. Out of 43 cases of PIH, 12 cases showed overlapping of these gross findings. Similar findings were seen in the study done by Ratnmala S. et al (2016) ${ }^{[21]}$ and Siva S.R. et al (2017). ${ }^{[22]}$

Microscopic examination of placenta was revealed prominent syncytial knots in 19/43 (44.18\%) cases, cytotrophoblastic proliferation $30 / 43(69.76 \%)$, there was increased incidence of calcification in present study 28/43 (65.11\%) cases, fibrinoid necrosis 7/43 (16.27\%). These findings were similar with the study done by Vijayalaxmi B. et al (2015) ${ }^{[23]}$ and Siva S.R. et al (2017). ${ }^{[22]}$

Placental Pathology in Cases of Anemia: There was 18/99 (18.18\%) cases of anemia causing IUFD. The frequency was comparable to study done by Patel S et al (2014). ${ }^{[9]}$ Gross examination of placenta revealed infarction in $7 / 18$ $(38.33 \%)$ cases, calcification in 8/18 (44.44\%) cases and retroplacental hematoma in $3 / 18(16.66 \%)$ cases, these findings were in accordance with study done by Ratnmala S. et al (2016) ${ }^{[21]}$ and A. Baske (2017). ${ }^{[24]}$

Microscopic examination revealed prominent syncytial knots 12/18 (66.66\%), fibrinoid necrosis 10/18 (55.55\%) and perivillous fibrin 11/18 (61.11\%) reflects uteroplacental insufficiency. Similar changes were seen in the study done by Ratnmala S. et al (2016) ${ }^{[21]}$ and A. Baske et al (2017). ${ }^{[24]}$

Placental Pathology in Cases of GDM : GDM causing IUFD noted in 3/99 cases which was similar to study done by Patel S et al (2016). ${ }^{[19]}$ Out of 3 cases of GDM, 2 cases on gross examination showed calcification, single case showed infarct and single umbilical artery. Similar findings were seen in study done by Salge AK et al (2012) ${ }^{[25]}$ Ratnmala S. et al (2016). ${ }^{[21]}$

On microscopic examination out of 3 cases, 2 cases showed chorioamnionitis of membrane, prominent syncytial knots and increased vascularity, and one case showed fibrinoid necrosis, intervillous hemorrhage, these findings were in accordance with the study done by Ratnmala S. et al (2016). ${ }^{[21]}$

Placenta in Cases of $\mathbf{R h}$ Incompatibility: $\mathrm{Rh}$ incompatibility was observed in two cases of IUFD, frequency of occurrence was in accordance with study done by Shagufta S et al(2006) ${ }^{[17]}$ and Dave A et al (2016). [10] Out of two cases of $\mathrm{Rh}$ incompatibility, on gross examination one placenta showed retroplacental hematoma and both had hydropic villi and intervillous hemorrhage microscopically.

Placenta in Viral hepatitis: A single case of viral hepatitis was noted causing IUFD, placental examination showed focal calcification on maternal surface. Microscopically it revealed perivillous fibrin and intervillous hemorrhage. Similar findings were observed in the study done by Dave A et al (2016). ${ }^{[10]}$

Placenta Pathology in Abruptio Placenta: Total 16/99 $(16.16 \%)$ cases belonged to abruption placenta which contributed to fetal deaths frequency of occurrence was in accordance with the study done by Prasanna $\mathrm{N}$ et al $(2015)^{[15]}$ and Patel S et al(2016). ${ }^{[19]}$ Gross examination of placenta showed retroplacental hematoma in $14 / 16(87.5 \%)$ cases, infarction 5/16 (31.25\%) cases and calcification $4 / 16$ (25\% cases).

Out of 16 cases of abruption placenta, microscopically prominent syncytial knots were noted in 3/16 (18.75\%) cases, increased vascularity and intervillous hemorrhage noted in $7 / 16(43.75 \%)$ cases and 10/16 (62.5\%) cases showed perivillous fibrin, stromal fibrosis in $7 / 16(43.75 \%)$ cases and 3 cases showed chorioamnionitis of membrane. 
Similar findings were noted in study done by Denise A et al (2010). ${ }^{[26]}$ (Table No.3)

Placenta in Oligohydramnios: Oligohydramnios was observed in 4/99 (4.04\%) cases. Grossly out of 4 cases; 2 placentas showed focal calcification on maternal surface with amnion nodosum. Microscopically prominent syncytial knots were observed in 3 cases and two cases showed amnion nodosum of membranes.

Various causes of placental pathology in the study are tabulated in Table No. 2. Gross and pathological changes noted in all case of the study are tabulated in table No.3 and 4.

\section{Conclusion}

In the comprehensive evaluation of intrauterine fetal death cases, placental examination contributes enormously, and can help to identify reasons for the demise of fetus. Placental study gives useful morphological information regarding the abnormality of pregnancy. In the present study pregnancy induced hypertension (PIH) was the most common cause $(43 \%)$ associated with maternal morbidity and intrauterine fetal deaths. PIH leads to uteroplacental insufficiency and shows various lesions in placenta viz. infarction, retroplacental hematoma and microscopically cytotrophoblastic proliferation, fibrinoid necrosis etc. The lesions in the placenta reflected the severity of the clinical manifestations in mother. Thus, the study of placental pathology gives clues to events occurring throughout gestation and can potentially help to answer, questions concerning pregnancy management and risk assessment of future pregnancies.

\section{Reference}

1. Fretts RC. Etiology and prevention of stillbirth. Am J Obstet Gynecol 2005; 193:1923-35.

2. Goldenberg RL, Kirby R, Culhane JF. Stillbirth:a review. J Matern fetal Neonatal Med 2004; 16:79-94

3. Burnley H, Moore I. An Audit to assess the quality of necropsies performed on stillborn infants. J clin pathol 2005; 58:93-4

4. Gordijin SJ, Erwich JJ, Khong TY. Value of the perinatal autopsy: critique. Pediatric Dev Pathol 2002; 5:480-8

5. Fleurisca J. Korteweg, Jan Jaap H.M. Erwich, Jozien P.Holm, Joke M.Ravise, Jan Van der Meer,Nic J.G.M.veeger,Albertus Timmer.American College of Obstetrician and Gynaecology. Diverse Placental Pathologies as the main cause of fetal death.2009;114:809

6. Estimate of mortality indicators-census of India websitevital statistics 2010;4:81.

7. Trevor macpherson: fact and fancy - what can we really tell from the placenta? Arch .pathol. Lab. Med. 115: 672-681.
8. Benirschke K: The Placenta in the context of History and Modern Medical Practice. Arch. Pathol. Lab. Med. 1991; 115: 663-667.

9. Patel S, Thaker R, Shah P, Majumder S. Study of causes and complications of intrauterine fetal death (IUFD). Int $\mathrm{J}$ Reprod Contracept Obstet Gynecol 2014; 3:931-5.

10. Dave A, Patidar R, Goyal S, Dave A. Intrauterine fetal demise-a tragic event: a study of its epidemiology, causes and methods of induction. Int $\mathrm{J}$ Reprod Contracept Obstet Gynecol 2016; 5:1316-21.

11. Nohr EA, Bech BH, Davies MJ, Morten, Frytenberg, Tine Brink Henriksen Jorn Olsen. Prepregnancy obesity and Fetal Death. American college of Obstetricians and Gynecologists. 2005; 106(2): 250-259.

12. Singh N, Pandey K, Gupta N, Arya AK, Pratap C, Naik R. A retrospective study of 296 cases of intrauterine fetal deaths at a tertiary care centre. Int $\mathrm{J}$ Reprod Contracept Obstet Gynecol 2013; 2:141-6.

13. Ujwala CH, shyamala Guruvare, Sudha S Bhat, lavanya Rai, Sugandhi Rao, Evaluation of placenta in Fetal Demise and Fetal growth Restriction. Journal of Clinical and Diagnostic Research. 2013;11:2530-2533

14. Sharma I, Bansal A. Eclampsia: maternal and perinatal outcome among tribal population of Bastar, Chhattisgarh, India in a tertiary care centre. Int J Reprod Contracept Obstet Gynecol 2016; 5:1887-91.

15. Prasanna N, Mahadevappa K, Antaratani RC, Lokare L. Cause of death and associated conditions of stillbirths. Int J Reprod Contracept Obstet Gynecol 2015; 4:1970-4.

16. Tamrakar SR, Chawla CD. Intrauterine Foetal Death and its Probable Causes: Two year Experience in Dhulikhel Hospital - Kathmandu University Hospital. Kathmandu Univ med J 2012; 10(4):44-48.

17. Shaheen S, Akhtar S. Causes of intrauterine foetal death. JPMI 2006; 209(3) :239-242.

18. Choudhary A, Gupta V. Epidemiology of Intrauterine Fetal Deaths: A Study In Tertiary Referral Centre In Uttarakhand. Journal of Dental and Medical Sciences (IOSR-JDMS) Mar. 2001;13 (3): 03-06.

19. Patel S, Sirpurkar M, Patel MS. A retrospective study to evaluate etiological factors associated with intrauterine fetal death at tertiary referral centre. Int $\mathrm{J}$ Reprod Contracept Obstet Gynecol 2016;5:970-5

20. Balu D, Nayak A, Swarup A. A study of intrauterine fetal death in a tertiary care hospital. Int $\mathrm{J}$ Reprod Contracept Obstet Gynecol 2015; 4:2028-31.

21. Patil SS, Siddheshware R, Sambarey PW. Clinical correlation with pathology of placenta in medical disorders of pregnancy and its comparison in normal pregnancy. Int $\mathbf{J}$ Reprod Contracept Obstet Gynecol 2017; 6:127-32.

22. Ranga SS. Adaline Thangam MK. Mallika V, Indira MV. Morphological and Histological Variations of Human Placenta in Hypertensive Disorders of Pregnancy. Int J Anat Res 2017; 5(1):3591-3598. 
23. Vijayalakshmi B, Sunitha Kitteli. "A Study of Histopathological Changes of Placenta in Pre Eclampsia and Perinatal Outcome". Journal of Evolution of Medical and Dental Sciences 2015; 4(67);11667-11673.

24. Baske A. Histological Changes of Placenta in Maternal Anemia. Indian Journal of Basic and Applied Medical Research. Sept 2017;06(4);78-87.
25. Salge AK, Rocha KM, Xavier RM, Ramalho WS, Rocha $\mathrm{E}^{\prime} \mathrm{L}$, Guimara ${ }^{\sim}$ es JV, et al. Macroscopic placental changes associated with fetal and maternal events in diabetes mellitus. Clinics. 2012; 67(10):1203-1208

26. Denise A. Elsasser, Cande V. Ananth, Vinay Prasad, Anthony M. Vintzileos. Diagnosis of Placental Abruption: Relationship between Clinical and Histopathological Findings. Eur J Obstet Gynecol Reprod Biol. 2010 February; 148(2):125.

*Corresponding author:

Dr. Pradnya Kale Jain, Mailing address- 286/ C, Sadashiv Peth, Pune 411030.

Phone: +919890281018

Email: pradnyaj.patho@gmail.com

Financial or other Competing Interests: None. 